\title{
Network-based resources for the innovation process of South African micro-entrepreneurs: A conceptual framework
}

\author{
E.W. Griffin-EL \\ Graduate School of Business \\ University of Cape Town \\ Private Bag X3, Rondebosch, 7701, South Africa \\ *To whom all correspondence should be addressed \\ eliada.griffin-el@gsb.uct.ac.za
}

\begin{abstract}
The paper explores the social networks of South African micro-entrepreneurs in order to understand the socially-embedded resources that micro-entrepreneurs apply towards their innovation process. The paper posits that the social capital embedded within the network of a micro-entrepreneur is activated by the demands of the innovation process to generate other forms of resources by which the innovation process is facilitated. Analysing empirical data collected via in-depth interviews of urban micro-entrepreneurs in the Johannesburg metropolitan area, the analysis conceptually organizes these various forms of socially embedded resources into an original framework referred to as Network Diversity Value (NDV). Two central dimensions frame NDV - the orientation of the innovation process and the form of the emerging resource. The interaction of these dimensions reveal a variety of network-based resources perceived as valuable, and suggest a greater degree of complexity and nuance in the South African micro-entrepreneur's innovative process than that which common discourse conveys.
\end{abstract}

\section{Introduction}

Innovation is a socially-embedded process, where relationships and social activity and exchange are noted to be driving factors of innovative thinking and activity (Oerlemans, Meeus, and Boekena, 1998; Landry, Amar, and Lamari, 2002; Akcomac and ter Weel, 2008). Where the literature argues social capital's positive contribution to innovation as well as its adversarial effects - due to the formation of insular groups that prevent access to new information and diverse communities (Florida, Cushing, and Gates, 2002; Dakhil and De Clercq, 2004), social capital is still noted to mediate the access to information and experiences that affect innovative activity. Hence, literature of economic sociology suggests that the entrepreneur's activity of recombining resources in order to create new products and processes is largely shaped by the entrepreneur's relationship with various actors. The dynamic engagement enabled by exchange of information and practice between the actors tied by each relationship lends to a process of novelty in output and approach.

Innovation among micro-entrepreneurs in urban areas of emerging markets - such as South Africa - is a process of which theoretical and empirical insight is expanding across both academic and practitioner circles. Readily, innovation literature has a provided a glance into the creative process of large, capital intensive firms or of the technological and knowledge industries (Tsai, 2001; Schilling and Phelps, 2007). This paper will explore the experience of idea formation, production, and commercialization of small firms operating in resource constrained areas - such as many South African townships - or of emerging, start-up firms by previously disadvantaged persons, such as the black South Africans. These formally-registered micro-enterprises are an unique business community authentic to South Africa in that they combine local nuance (i.e. indigenous material, contextual challenges, prevailing ideas, and cultural mores) with cutting-edge trends in order to provide products and services that represent a contemporary South Africa to the rest of the nation and world. Hence, as the nation prioritizes entrepreneurial development as a central part of local economic development, a source of job growth, and promoters of home-grown products to a national and global marketplace, the focus upon micro-firms has important policy and program implications (www.dti.gov; Review of Ten Years of Small Business Support in South Africa, 2004; The State of Entrepreneurship in South Africa, 2009). This paper argues that it is paramount to understand how these set of South African entrepreneurs draw the needed support and resources by which to carry out this innovative process from social capital when other capital resources, especially that of financial capital, are usually initially scarce.

The purpose of this paper is to present a conceptual typological framework of the non-financial resources which South African micro-entrepreneurs perceive to source from their social networks and apply towards their innovation process. Through qualitative data collection and analysis, the study reveals an array of tangible and intangible resources deemed 'valuable' by micro-enterprises in order to facilitate the innovation process and overcome their resource constraints. The study provides a theoretical categorization of these resources by identifying the prevailing variables of 'form' and 'orientation,' and how the interaction between these two concepts frame a variety of entrepreneurial 
resources which are embedded in the entrepreneur's social network. The purpose of this paper is to illuminate the broad array of important components for entrepreneurial development- beyond the commonly cited component of finance - that micro-entrepreneurs value in securing their firms' viability.

Entrepreneurial journeys across the world readily illustrate that, despite not having formal finance, some enterprises have flourished; on the other hand, even with loans, grants, and equity, some have failed. This paper hopes to add complexity to the discourse around the resources needed for entrepreneurs of initial resource-constrained conditions to innovate. Employing an economic sociological lens to explore the entrepreneurial process of micro-firms, this paper focuses upon the nuanced engagement between entrepreneurs and their social environment to employ their social capital in acquiring other various forms of capital to move their innovation process forward. Micro-firms are defined loosely in this study as those formal enterprises that employ 10 fulltime employees or less. This defining criteria is derived from the SMME Classification sourced from Section 1 of the National Small Business Act of 1996 (and later amended in 2003 and 2004), where micro-businesses are defined in having, on average, 5 full time employees, but less than 20, at which point they would be classified as very small businesses (Mahembe, 2011). Micro-enterprises represent an entrepreneurial phenomenon that is highly visible and prevalent across the South African economy, as such firms are noted to represent more than $90 \%$ of total medium, small, and micro-enterprises in South Africa, and contribute between $53 \%-61 \%$ of total employment (Mahembe, 2011).

Qualitative data was collected via semi-structured interviews with thirty formally registered micro-enterprises of the broader Johannesburg metropolitan area. Enterprises featured were situated in Johannesburg townships, suburbs, and the central business district. The interview protocol, a revised version of Abigail Barr's (1998) Network Diversity Questionnaire, was employed to inform the broader research question of 'How does the South African micro-entrepreneur utilize their social networks towards the progress of their venture?' The findings, analysed via grounded theory methodology, unveiled the various resources that microentrepreneurs in resource-constrained conditions draw from their relationships referring to the conceptual framework of Network Diversity Value (NDV). The analysis revealed form and orientation as the central dimensions of NDV; the interactions of these dimensions describe the different types of value derived from micro-entrepreneurs' social networks as derived from the data. A broader conceptualization of the findings suggest that microenterprises cultivate and acquire multiple forms of non-financial capital - termed here as functional, cognitive, and socio-cultural - from the social capital generated within their relationships. Additionally, however, these various capital forms are oriented towards distinct parts of the entrepreneurial process. In this regard, the categorical 'form of capital' is expressed in various ways as informed by the process they are oriented towards. The three orientations of value derived from the data speak to application towards the conceptualization-, capacity-, and customer-building processes involved in the innovative process of entrepreneurship. These three orientations cross with the three forms of capital to describe an array of nonfinancial resources that are socially embedded in the microentrepreneur's network.

\section{Literature}

Drawing theoretical inspiration from the structural embeddedness perspective and social capital literature, the study builds upon the underpinning assertions that economic behaviour and transactions that constitute the market are embedded in social relationships (Granovetter, 1985; Zukin and DiMaggio, 1990). Hence, entrepreneurs - as both social and economic actors - readily engage with their surrounding social structure to source the knowledge, skills, exposure, and materials needed to carry out their entrepreneurial activity. The purpose of the paper is to illuminate the identification and acquisition of socially embedded resources from microentrepreneurs' social networks.

Entrepreneurial literature broadly notes the role of networks in entrepreneurial practice. Networks are increasingly studied for their contribution to an enterprises performance and outcomes as they are noted to provide a variety of useful resources to the entrepreneurial experience (Hoang and Anconcic, 2003). Hence, the resource perspective of entrepreneurial networks sheds light on the flow of knowledge, access to new markets and implementing other strategies of internationalization, supplier of needed inputs, and provider of technology and finance that relationships enable (Pittaway, Robertson, Munir, Denyer, and Neely, 2004). Hite and Hesterly (2001) postulate that as a small growing firm evolves, and the amount and type of resources needed changes, so also does the network structure in which the firm is embedded. Hence, this resource perspective of the network not only proposes that the network is a determining factor in the type and accessibility of resources, but that the changing resource needs also shapes the structure of the network. Furthermore, cluster studies illuminate the dimension of closeness and proximity as a factor in rate and potency at which intangible and tangible resources are shared (Fleming et al, 2007; Tallman and Phene, 2007).

Innovative activity that takes place within the entrepreneurial process is noted to thrive within certain arrangements of social relationships (Schilling and Phelps, 2007). Schilling and Phelps (2007) further emphasize that the structure of the network - in terms of the length and closeness of its ties influences whether or not a firm has high innovative output, implying that the structure determines to which resources a firm readily has access. Positioning within the network does the same, as a firm's placement in their own network can inform the knowledge resources they are able to acquire (Tsai, 2001). This arguably holds true for small firms as well. As Lipparini and Sobrero (1994) argue, a small firm's network structure can be the source of their competitive advantage, providing them access to certain distinct resources, which distinguishes its innovative process. Rogers (2004) emphasizes that the type of sector makes a difference, 
illustrating that small manufacturing firms are most likely to harness their network resources for innovation than small firms of other sectors.

To further explore the theoretical underpinnings of the origins of network resources that play such a central role in entrepreneurial innovation, the social capital literature offers useful insight. Pierre Bourdieu's (1986) seminal work highlights the resource that is embedded in relationships, and offers popularity to the term social capital. His work extends the conceptualization of capital beyond the single idea of economic capital made central to the prevailing discourse around economic development. He asserts that capital not only exists in multiple forms beyond that which is transacted, but in many ways, they facilitate the transaction, and hence are convertible into each other. This assertion provides the foundational premise to this study, as it seeks to explore what other forms of capital are drawn from the social capital existing within the social relations that constitute a microentrepreneur's social network.

Bourdieu (1986) loosely defines social capital as both the network of institutionalized relationships to which an actor belongs, and in turn, the resources that are derived - either in the short or long term - from these relationships. Social capital has become a concept of discussion in the economic development literature (Woolcock 1998, 2002; Woolcock and Narayan, 2000; Fukuyama, 2006). Literature has highlighted the valuable resources - both intangible such as trust and information, and tangible, such as facilities and finance - that can be drawn from other actors with whom they have a relationship. The relationships serve as a necessary part in cultivating a market environment that facilitates the exchange and transactions between actors. Adversely, when social capital is negative, or non-existent, it can lead to low or malfeasant economic activity (Streeten, 2002; Putman, 2003; Garcia, 2006). Hence social capital is a concept of intriguing focus for the performance of economic actors, including entrepreneurs. As Alejandro Portes notes in his research of immigrant entrepreneurs, social capital assists entrepreneurs in building their firms by allowing them access to certain resources and items via the people they are connected to and identify with through common experience and shared identity (Portes and Sensenbrenner, 2003; Portes, 2008). Similarly, this study - as others that highlight entrepreneurial phenomenon within the South African empirical context (Urban, 2011) seeks to extend this premise to micro-entrepreneurs of the South African landscape. Unlike Bourdieu (1986), who specifically speaks of social capital with regards to the distribution of power and privilege, this study does extend that discussion of socially embedded access and power directly. Rather, it builds upon the conceptualization of social capital to address a query about networks - as a facilitator of social capital - and their role in the innovative process of micro-entrepreneurship.

Networks' role in providing a myriad of resources valuable to an entrepreneur's progress, and the assertion that social capital is generated in these networked relationships, affirms the premise that social capital can be a source of other forms of capital. In this regard, Bourdieu's thesis concerning the convertibility of capital from one form to another provides insight towards understanding the variety of resources that are generated by social capital in networks. As literature has listed network-facilitated resources, there is no conceptual framework to usefully layout the dimensions of various socially-embedded entrepreneurial resources and, in turn, the multiple resources represented by the different combinations of these dimensions, particularly in the context of microentrepreneurship in resource constrained areas. This paper hopes to intersect the innovation and social capital literature as it applies to the entrepreneurial process of small firms in the context of African economies in order to contribute to a rethinking of emerging entrepreneurial practice and the social structure that supports it. The African economy is noted to be undergoing high growth rates and a noteworthy decrease in poverty related conditions, positioning it as a continent of high attraction to investment, according to the World Bank's Chief Economist for the Africa Region, Shanta Devarajan (2010). Hence, the cultivation of entrepreneurial innovation is even more pertinent at a critical shift in economic development, political stability, and social development. Ultimately, the analysis intends to lay out a conceptual model of the different forms of capital that emerge from microentrepreneurs relations, as well as the part of the entrepreneurial process towards which these items are oriented. Such a conceptual model is intended to contribute to the broader discourse around shaping an enabling environment for entrepreneurial development in South Africa by suggesting the entrepreneurial contribution of certain specific relationships that exist in a micro-entrepreneur's social ecosystem. Moreover, such a model is hoped to have implications for highlighting and encouraging the inclusion of the social dimensions of innovation in the discussions of how to foster entrepreneurship for micro-enterprises emerging from resource-constrained communities and driven by entrepreneurs from historically-disadvantaged backgrounds.

\section{Methodology}

The study employs the data analytical method of grounded theory analysis in order to capture a theoretical framework derived directly from the data. The data collection features thirty cases of micro-entrepreneurs in the broader Johannesburg Metropolitan area of South Africa.

Entrepreneurial research in general, as Makela and Turcan (2007) suggest, has room to be enriched by the capturing of nuanced factors. Grounded theory analysis, like most qualitative analyses, guides the investigator towards identifying abstract themes from the raw data. Grounded theory's distinguishing objective is to derive an original 'theory' from the data which conceptually captures the intrinsic process of the phenomenon being studied (Glaser and Strauss, 1967). Beyond the initial phase of thematic coding, analysis also entails a constant comparison and categorization of codes to gradually reveal the main concepts of the emerging theory. Upon reaching theoretical saturation, the central conceptual category is identified to which all other conceptual categories relate to build an explicatory narrative 
of the phenomenon. Propositions can be formed to be tested in future studies (Glaser and Strauss, 1967; Strauss and Corbin, 1990)

Grounded theory lays out a three-phase systematic analytical process by which to undergo analytical process of interpretation and meaning-making from qualitative data. At the centre of this process, as with most qualitative analysis methods, are the constant comparison of codes and their categorization into broader more abstract themes, referred to as categories. In this study initial codes were derived through a manual, color-coded process of de-condensing the data from the in-depth interviews into smaller meaningful segments of information. This first step is referred to as open coding. The formation of categories via the clustering of these codes that describe similar themes or speak to a similar part of the broader phenomenon, refers to the axial- or second stage - of coding. The categories form the basis of the conceptual construction derived directly from the data. At the final state of analysis, categories are then related to each other to constitute the 'story' behind the phenomenon, or in other words, the emerging theoretical framework. That emerging theoretical framework of the network resources converted from micro-entrepreneurs' social capital is what I present in this paper.

\section{Research participants}

Data was collected via in-depth, semi-structured interviews with thirty micro-sized South African firms. The sample was constructed via random selection of willing, available firms from The Business Place Opportunity Exchange Database, The Johannesburg Fashion Week listings, and to a lesser extent, the convenient snowball method via referrals. 'Micro' in this study is defined as firms hiring ten or less full-time employees, where approximately $47 \%$ of the respondents interviewed hired at least one employee. All the businesses were formally registered in South Africa and all the entrepreneurs were African South Africans. The median age of the business organizations was three years, $50 \%$ of the entrepreneurs themselves fell within the ages of 25 and 30, and $47 \%$ of entrepreneurs operated their businesses from the Central Business District of Johannesburg. The remaining were based in the broader Johannesburg metropolitan area consisting of the surrounding townships, suburbs, and towns - such as Soweto, Vosloorus, Benoni, Alberton, and Vereeninging in the Vaal. The thirty cases primarily represented the industries of fashion manufacturing, construction, media and publicity, and health and wellness.

\section{Data collection}

The interview instrument used for this study was a revised version of Abigail Barr's original Entrepreneurial Network Diversity Questionnaire used for her study of the Ghanaian manufacturing industry in Accra, Ghana (1995). South African entrepreneurs were asked of their relationship with eight entities - 1) similar entrepreneurs; 2) different entrepreneurs; 3) entrepreneurs in other South African provinces; 4) entrepreneurs in other countries; 5) immigrant entrepreneurs; 6) larger businesses; 7) government; and 8) financial institutions.

Each entrepreneur was asked a set of questions pertaining to their relationship with each category of actors. The qualitative data analysed in this study is in response to the question "Are relationships with actors under this category valuable to your business? How so?"

\section{Data analysis and findings}

Qualitative analysis of the data collected from the 30 microentrepreneurial cases revealed a variety of socially-embedded resources perceived by respondents to add entrepreneurial value to the innovation process of their venture. Responses to the general question of 'how do South African small entrepreneurs utilize their networks to contribute to their venture's development?' and more specifically, "How is this relationship valuable to your business?." unearthed the data that was then coded and aggregated to form the overarching conceptual framework of Network Diversity Value (NDV). NDV refers to the entrepreneurially valuable resources, which an entrepreneur perceives to source from the diverse relationships of his or her network. I observed how these resources - both intangible and tangible - were applied throughout the innovation process.

NDV is framed by the interaction of its two prevailing categories - form and orientation. The orientation of Network Diversity Value refers to the area or part of the innovation process towards which the resource is primarily applied and assists in facilitating. Data revealed that entrepreneurial resources drawn from their networks were largely oriented towards the parts if the innovation process: the idea formation, or conceptualization, of the product or service; the creative augmentation of operational and organizational capacity by which to produce the product or deliver the service-often times in the midst of constraining factors; and the strengthening of customer relations in order to appeal to a current or potential market.

The form refers to the qualitative nature of the resource, seeking to capture the prevailing characteristics of different types of capital. The data suggested that non-financial network-based resources of entrepreneurial value seem to come in three primary forms. They emerge in a functional form, referring to resources of strict instrumental value and often a physical item, such as machinery. Entrepreneurial resources also appeared in a cognitive form, describing the sets of knowledge and technical information and the procedures involved in making sense of them. Thirdly, entrepreneurial resources came in the form of socio-cultural resources, referring to the acquired understanding of prevailing social and cultural dynamics that shape popular discourse and preferences within society.

These three forms and orientations of Network Diversity Value interact with each other to reveal a variety of networkbased entrepreneurial resources perceived to be useful to the micro-entrepreneur's innovation process. The following 
diagram conveys the interaction between form and orientation, and list examples of the entrepreneurial resources that are informed by the interaction between both concepts. The following section will then elaborate upon these socially- embedded entrepreneurial resources, first explaining each orientation in greater depth, and then describing the nature of each form within each respective orientation as informed by the data.

Table 1: Network diversity value framework

\begin{tabular}{|l|l|l|l|}
\hline $\begin{array}{l}\text { Orientations of Network } \\
\text { Diversity Value }\end{array}$ & \multicolumn{3}{|c|}{ Forms of Network Diversity Value } \\
\hline & Functional & Cognitive & Socio-cultural \\
\hline Conceptualization & $\begin{array}{l}\text { Specialized tools, software; } \\
\text { untested materials; new } \\
\text { technology }\end{array}$ & Mentoring, internships & $\begin{array}{l}\text { Social, political, and cultural phenomenon; } \\
\text { Global events and local trends }\end{array}$ \\
\hline Capacity & $\begin{array}{l}\text { Machinery, office and studio } \\
\text { space, materials, vending space }\end{array}$ & $\begin{array}{l}\text { Management courses and } \\
\text { training, skills acquisition } \\
\text { workshops }\end{array}$ & Global and local exposure \\
\hline Customer & Website, marketing material & $\begin{array}{l}\text { Networking experiences, } \\
\text { relationship building }\end{array}$ & $\begin{array}{l}\text { Identified shared experience and identity } \\
\text { with customer base }\end{array}$ \\
\hline
\end{tabular}

\section{Conceptualization-orientation of the innovation process}

Concept-oriented value refers to the value derived from an entrepreneur's network that contributes to what the entrepreneur produces. This orientation specifically describes the process in conceiving the nature and design of the good or service that distinguishes it from others. Conceptualization-oriented value consists of various types of information, opportunities for exposure, and resources that enable the entrepreneur to conceptualize and create a product that is more responsive to a specific market demand. Criteria such as quality, style, and functionality are taken into account. The following business partners, for example, switched from mainly featuring one concept of a clothing garment to another after realizing that the latter had a larger market.

"We started do, um, sleepwear. And then we said, let's not focus on sleepwear. So now we are doing weddings nowwedding gowns, bridesmaids dresses..." $\sim O$ and $M$

\section{Functional form of NDV with a conceptualization orientation}

Concept-oriented value can also be found in discovery of new inputs - such as materials and technology - that alter the method of production or the substance by which products are made. Access to new material and infrastructure expands the scope within which an entrepreneur can imagine - and construct - a new product or service. Inputs formally perceived as waste, material from a foreign country, cutting edge and specialized machinery enhanced entrepreneurs' ability to conceive a new products, particularly in the fashion manufacturing sector. Within the service industries, internet access, social media platforms, and new and improved ingredients were very useful in conceiving new services, particularly in the media and health and wellness industries.

As the entrepreneur articulates below, her creation of women's dresses using an obscure fabric formed her niche in the clothing industry and successfully launched her into the industry. The discovery of new applications for a common material made way for new conceptualizations of women clothing and informed a distinct offering in the marketplace.

"Yes. It [referring to a certain fabric] comes like a suit like this. Some people, they don't even think they can do anything - a big thing out of it because normally it's a trim that they just put for pants, for collars, for you know, on the track suits. He [God] gave me that vision - that top. First thing in the morning, I just go straight to work and then I cut the fabric and I did it. And 'wa-lah' it all started." $\sim M$

The entrepreneur saw the alternative use of the 'track suit trim' and was able to convert this common material into a new apparel innovation. The statement illustrates the instrumental use of the material to form the new physical composition of the innovation.

\section{Cognitive form of NDV with a conceptualization orientation}

Items and information of concept-oriented value help to enhance product creation via facilitating exposure to new ideas and trends on both a local and global scale. Such information and items also introduce entrepreneurs to new technologies and sources of affordable inputs. Aspects of innovation-oriented value focus outwardly on the surrounding conditions of the organization and apply such information to the production abilities of the organization.

As illustrated in the relationship between South African micro-entrepreneurs and immigrant entrepreneurs in the garment industry, micro-entrepreneurs would readily consult immigrant garment entrepreneurs whose expertise from their home country provides a specialized skill or knowledge in garment in design that is not common in South Africa. As a result, working with such entrepreneurs would facilitate an exchange of unique knowledge and exposure by which the conceptualization of African garments would be expanded. In some arrangements, micro- entrepreneur would maintains the central decision-making authority, as they incorporate the immigrant entrepreneurs' skills into their value chains. In 
others, they would establish a joint-agreement - where the decision-making, as well as the process of production, was more equally shared reflecting a more equitable and collaborative design process. Regardless of the arrangement, the boundaries of conceptualization would be stretched with the familiarity to new design abilities.

\section{Socio-cultural form of NDV with a conceptualization orientation}

Another form of concept-oriented value is the knowledge of prevailing social ideas in contemporary society. These social ideas include reigning themes of identity formation among segments of the South African community - such as youth, women, urban residents, or black South Africans. Messages of these social ideas tend to express insight or critique of prevailing norms and controversy in current times with references to politics, culture, history, and world affairs. Sources of these social ideas are made prominent via music, revered political figures, and international events. In this regard, as the following entrepreneur illustrates, clothing designers experiment with ideas of the times and explore means by which to express these ideas in the wardrobes of both the young and urban generation.

"It's (referring to her new fashion creation)... got underlying, like sort of political issues. It's, it's inference on world cultures, a little bit of this and a little bit of that. - not...it's not all out...tribal." $\sim S$

Entrepreneur $S$ draws upon cultural themes and political sentiments from throughout the globe to invoke a new vision of apparel innovation. On the other hand, entrepreneurs $W$ and $S$ - although recognizing the presence of artistic expression from other parts of the world in their community, they source inspiration from the prevailing style, activity and discourse of the local context of the township.

"Because our concept is to actually show people that side...that stigma of just being a township...it's just a regular day, hard day, you know... although it is Soweto... Yeah, we, we, we're not trying to be someone else, you know. We, we are not trying to be Europeans or be -no, no, no. No, no, no. No, we are not trying to be like that. We might be influenced by hip-hop music, by house music, ehhhh, by, maybe we play rock music, You know, there are a whole lot of influences...but at the end of the day, we're doing our own thesis. You know, we do our own report....Wear your own style. Wear your own identity, wear your own culture." $\sim W \& M$

Moreover, the entrepreneur below conveys how news innovation can be conceptualized by the ideas that come from the globe's interaction with the local context. In this regard, understanding the mind and the experience of tourists, as entrepreneur $F$ goes on to explain below, is an example of socio-cultural value sourced from not just global or local influences, but the engagement between the two.
“I've just completed a portfolio for one shop in Rosebank. ...I'm trying to do some basic research before going there. And understand, more tourist go there. And you know, tourist, they like everything that remind them of Africa." $\sim \mathrm{F}$

\section{Capacity-orientation of the innovation process}

Capacity-oriented value refers to the factors derived from an entrepreneur's social network, which contribute to how much and how well the entrepreneur's small business is able to produce a good or provide a service. These aspects of value assist in augmenting the small entrepreneur's capacity to operate soundly, produce efficiently, and respond effectively to shifts in demand. The data revealed that as entrepreneurs interacted with a variety of contacts, from similar businesses to public incubators and business development services, such interaction facilitates the sharing or transfer of resources that the entrepreneur utilizes in order to improve their operational strategy and organizational structure.

\section{Functional form of NDV with a capacity orientation}

In several cases, the acquisition of capacity-oriented value would be enabled via the combining of production capacities by which to better meet a burgeoning market and capitalize upon emerging opportunities. Such business integration can manifest itself in several forms. Data revealed, for example, that some small businesses would integrate other small businesses' services into their production line so as to achieve the desired volume of output or quality of product without having to bear greater costs in hiring employees. Other small entrepreneurs - as a way of increasing their operational capacity and expanding their organizational scope, for example - chose to occasionally outsource a segment of their manufacturing process as a way of achieving the same end. The entrepreneur below, for example, noted how bringing in another entrepreneur with a specialized skill expands her company's capacity to add value to an innovation and provide something novel on the market.

"You know what she does, she works with --- beads and
embroidery... and beads, that's her signature. Bead-work
and embroidery. And for her embroidery, she got
somebody from Senegal to do that. And that person is very
good. So just the fabric, she can change this fabric - the
plain one, and do her embroidery, and the fabric will be
something else." $\sim F$

Furthermore, physical examples of resources in the functional form, oriented towards the capacity-building of microentrepreneurs include workspace, machinery, or vehicles of labour. Different relationships provide entrepreneurs with capacity-oriented capital in this form, from relationships with large companies to that of similar emerging firms. The entrepreneurs below highlight how their interaction with a large corporation via a business competition awarded them necessary machinery by which to increase their production capacity. 
“...DeBeers...the diamond company... They bought us all these machines. And some of the stuff that we use in the studio. While they started...they gave us a jumpstart..." $\sim M \& W$

In contrast to entrepreneurs $\mathrm{M}$ and $\mathrm{W}$, entrepreneur $\mathrm{MM}$ below was able to locate retail space - increasing her capacity to reach her targeted market - via the connection to another similar entrepreneur.

“...April, I took, I took my stuff, and went to the Bruma - you know Bruma flee market?... I went there and I got a stall. The stall, it was R160. We shared with one lady. We shared a stall..." $\sim M M$

\section{Cognitive form of NDV with a capacity orientation}

Educational workshops and consulting services from different relationships also provide capacity-oriented value in assisting the entrepreneur in streamlining and improving their knowledge and understanding of building an effective operational strategy. Specifically, such educational exposure would involve, for example, technical assistance for entrepreneurs undergoing complicated legal and administrative procedures or detailed instructions for difficult processes towards enhancing business structure and strategy to capitalize upon new opportunities.

"Yeah, it's services (referring to a business development firm) are like for people who are tendering. They (referring to entrepreneurs) will have to learn the business - how to tender...how to go through a process of tendering. And then, they are going to provide inside, inside jobs which are tenders. Yeah, they are going to provide tenders for those people who have registered with them and then they are going to help with filling out the tender document." $\sim S K$

The statement above illustrates how the acquisition of knowledge in the tender procedure - made possible with relationships with particular information-bearing agencies and organizations - increases the entrepreneur's capacity to be eligible and apply for these business opportunities.

Data revealed this resource of personal and organizational learning of entrepreneurs gained enrichment also came from new business activities achieved through integrating business capacities with other small firms. Such integration would demand new areas of knowledge and familiarity with new systems and institutions. Ideas and costs shared in business partnerships allowed for the co-creation and negotiation of knowledge and meaning from which more innovative practices can emerge. Furthermore, networks allowed for the acquisition of needed assistance and expertise via the inclusion of employees and interns.

\section{Socio-cultural form of NDV with a capacity orientation}

Acculturation to the assumptions and norms of the business domain is an acquired understanding that proved new to several of the entrepreneurs featured in the study, and yet, essential in the strategic shaping of their business structure and capacity to perform. For several, starting a business was a novel - and an unfamiliar - process to undergo. Although several pursued entrepreneurship because of opportunities identified in the market, the practice of designing and executing a business strategy, and the technical discourse, which often informs this process, was new and often intimidating. Moreover, the necessary business acumen included becoming versatile in esoteric business terminology and functions, but also, shaping one's entrepreneurial image and organization brand. Understanding the socialized elements of the business world (i.e. modes of behaviour, communication, assertiveness, business astuteness, etc.) also had to be learned. In short, an entrepreneur's capacity as a businessperson and the acculturation into the business domain was also largely enhanced through the continuous engagement with larger business, peer firms, and mentoring entrepreneurs.

"There was a college in East Rand, the college is still there, a course - how to start your own business. And, oh, I got a (taste) of it in UNISA - Business management... Um, I don't know what happened. Maybe it's because it's very expensive, or what, but it was so helpful. Because it teaches about expanding your business. The little things that you are not aware of, it can make your business to expand." $\sim P$

In this excerpt, the entrepreneur emphasizes their enhanced awareness of what it takes to run a business, suggesting important social and entrepreneurial cues acquired to enrich their business-management capacity.

Capacity-oriented value of a socio-cultural form included a sophistication of management skills that contributed to their personal growth in vision, resolve, creativity, and perseverance that guides the entrepreneur through both the triumphant and difficult times of running a business. The micro-entrepreneurs also noted that inspiration drawn from other entrepreneurs' success stories highlighted noteworthy ideals, such as integrity and perseverance, as necessary attributes of their entrepreneurial experience. Furthermore, such resources edify an entrepreneur's understanding of people and meaningful ways by which to promote a sense of leadership, ownership, and cooperation among their staff.

\section{Customer-building orientation of the innovation process}

Customer-oriented value are the factors derived from networks that contribute to the entrepreneur's deepened understanding of who they are producing for. These factors were described as helpful in assisting a small entrepreneur in accessing new markets that may increase clientele, further diversify their customer base, or appeal to customers of a niche market. Information of this regard would consist of the market size, as well as various criteria such as demographics, social position, and geographic location that informs customers' purchasing decisions. 


\section{Functional form of NDV that is customer-oriented}

Of the many management skills that entrepreneurs emphasized as essential in running their business, particular attention was given to the merits of properly understanding the useful tools behind marketing and branding their business. Micro-entrepreneurs would express pleasure in stating the establishment of their website, recognized across the respondents as necessary platform in conveying the legitimacy of the business and providing as suitable business 'face' to clients. The development of business logos also served as a highly-prioritized tool for articulating the business to the customer. Micro-entrepreneurs would credit different voucher programs with business development organizations, such as Umsobomvu and The Business Place, in enabling graphic design services by which their logo could be designed. Similarly assistance from incubator relationships would develop other tools such as business cards, pamphlets, and brochures - all treasured marketing tools of the microentrepreneur by which to portray a credible image of their business and offerings to the customer.

"Ummmm, I think the, the information on how to - okay, normally here, they even do workshops, you know, in the Business Place. And the information on how to, you know, how to access the funding - we had a workshop like that and uh, the importance of marketing, marketing the business, not only with a, with a business card or the word of mouth. Maybe having the website, having the billboards, networking, the importance of marketing. And once you don't market your business, it will never grow." $\sim M$

This entrepreneur emphasizes the needs for actual tools and resources in order to effectively market the enterprise to its desired customer base. This suggest that relationships that facilitate access to platforms, technology, and material used to attract customers are an important type of capital converted from social capital.

Communication infrastructural systems - such as constant access to the internet via internet kiosks and available computers for correspondence and word processing, were noted as very important by the micro-entrepreneurs. They stated the high expense in accessing these facilities elsewhere, and hence, the gratitude towards incubator relationships for making these facilities available. Several stated that if there were more steady access to the Internet, they believe they would be able to expand their customer base and promote their offerings more broadly.

\section{Cognitive form of NDV that is customer-oriented}

Cognitive resources of customer-oriented value included the skills and know-how of image building. Entrepreneurs believed that such skills would enable them to better communicate their identity to selected consumer bases. They understood that as small enterprises, they were still vulnerable to both local and global competitive pressure. Yet, as small enterprises emerging directly from the South African social context, they possessed a nuanced understanding of the savvy, urban, and expressive generation of increasing purchasing power to whom they would be marketing a particular lifestyle that their products conveyed. Hence, the acumen by which to pinpoint such audiences, the language by which to frame one's business that grab's their attention, and the relationship-building skills by which to secure a clientele by shared purpose became paramount. Additionally, the skills involved in network building - by which entrepreneurs learn of opportunities to showcase their wares or services and promote their brand are a central cognitive form. As several micro-entrepreneurs were intrigued with the possibilities of extending their targeted market to other areas in the world, the competencies involved in internationalizing one's firm which offers the possibility of distributing goods and/or services through a global market - were also important cognitive values with a customer-orientation.

\section{Socio-cultural form of NDV that is customer-oriented}

Knowledge of prevailing themes in popular culture, economics, gender and cultural themes, the impact of global events, communities of increasing purchasing power, and consumption trends are examples of information with customer-oriented value.

The statement below illustrates, for example, how an entrepreneur's sensitivities to women's perspectives of certain issues informs how she positions the product to appeal to women.

“Um, yeah I think my stuff's very wearable. I like it to be - I like women to identify with it... there are certain parts with it that deals with certain women's issues. You know, for me, the research I have done behind it has all these issues, but maybe - I hope it comes across but it is not blatant." $\sim S$

Customers' choices and preferences are shaped by prevailing themes in popular culture, as well as primary current events. Hence, entrepreneurs expressed value in information about political and social trends within South Africa, which helps them to better understand the attitude of the market segment they are producing for. Similar to the quote above, the entrepreneur below expresses the importance of knowing 'what is happening' within the local context so as to know how to communicate the relevance of the product.

"Yeah, not abroad - information about the market, the styles, what is happening - Here in South Africa. I mean, before you go abroad, you need to know what is happening here, you know?... And if I'm a buyer, and I want to introduce some style in South Africa, maybe I am working for, I'm a buyer from I.T., I need to know my country first before I can go outside. Yeah..." $\sim O$

In addition to the local focus, conceptualizations of identity and community are increasingly shaped by global ideas as well. Therefore, some entrepreneurs recognized understanding the broader cultural atmosphere and exchanges 
of ideas across a global forum as critical in understanding their customers. As with the case of innovating products and services, information of customer-oriented value equip entrepreneurs to developing their own niche while also learning how to manoeuvre more effectively through their market.

“...Business books, political books, social books. I mean autobiographies - you, uhhhhh, like for instance (Jack) Danson, your Thabo Mbeki, uhhh, Chiko Onyenia, I've done your... Steve Biko, Richard Gilsakie...Art of War... It's like, for (name of company) I think, whatever that you see, was -was done once. For me, if I didn't read those books, I wouldn't even have a thought of opening a shop...because all that information gives you reason - it's that reasoning in developing your own method, your own values." $\sim W$

As suggested by evidence of the data above, information about societal trends in politics, popular culture, economics, gender issues and many more contemporary topics are valuable in designing a marketing strategy. This information is drawn from a variety of sources. As mentioned above, books remain a constant reference of ideas and knowledge. Additionally, the internet was increasingly referred to as a heavily consulted source, as well as media resources, such as magazines and the television.

\section{Discussion and conclusion}

The conceptual model of network diversity value reveals that resources derived from an entrepreneur's networks are the product of the interaction between the structure of the network and the innovation process. The analysis posits that social capital, which is embedded in the ties that constitute the structure of the network, help to facilitate and shape the innovation process of micro-entrepreneurs.

Moreover, the analytical findings may postulate that social capital creates different forms of entrepreneurial resources contingent upon the demands of the innovation process at any given time and space of the entrepreneur's experience. The next postulation offered is that social capital is activated by the demands unique to distinct parts of the innovation process, and in turn, facilitates the emergence of the necessary resources in order to carry out that part of the innovation process. Hence, we further postulate that the orientation of the innovative process informs the emerging forms of entrepreneurially-valuable resources that are derived from the social capital inherent in micro- entrepreneur's surrounding relationships. Hence, this postulation further builds upon the premise of Bourdieu (1986) and subsequent literature that social capital has a property of convertibility into other forms of capital. Moreover, however, the analysis - depicted via the two-dimensional model- provides a nuanced but organized conceptual schematic of how social capital is converted into other capital resources as microentrepreneurs interact with their network in lieu of their innovation process.
The framework of Network Diversity Value is organized around the cross-tabulation of the two dimensions, form and orientation. In attempts to understand the relationship between these dimensions, and its implications for the conceptualization of social capital, the third postulation offered from the analysis is that social capital serves as the mediating element between the orientation of the innovation process of South African micro-entrepreneurs and the form of resources that are eventually acquired. Such a postulation aids in further unravelling the intersection between innovation and social capital literature, particularly within the context of the micro-entrepreneurial phenomenon. The general assertion, as mentioned before, which links both literatures, is that innovation is a socially-embedded process. Hence, the underlying assumption here is that the process of creating and recombining resources to produce novel approaches and products is largely facilitated by the relationships that an entrepreneur forms which enables the formation of various resources, such as the exchange of information, material, access, and exposure between two or more people. Innovation literature touches upon the significance of structure of networks, but resources are rarely placed within the frame of social capital. Understanding resources drawn from networks for the innovation process can contribute to a nuanced understanding of the convertibility of social capital into other forms of entrepreneurially-relevant capital. This study hopes to add that assertion that the resources that are derived from social capital towards the application of the innovative process are much more nuanced and varied. Furthermore this nuance and variation can be conceptually organized in a systematic way. Network diversity value represents the conceptual organization of the variation of resources derived from social capital towards the innovation process of entrepreneurial activity.

As a result, network diversity value offers a complexity to the experience of emerging entrepreneurs often generalized to be necessity-driven, subsistent, poor, or low impact. Such small firms owned by members South Africa's historically disadvantaged communities are often perceived to be simplistic in their conceptualization of products and services, and hence, the subsequent processes that bring these products to market are also presumed to be uncreative, duplicative, and uncomplicated (Barr, 2002; Fafchamps and Minten, 2003). Furthermore, enterprises that are owned by members of certain ethnic and gender communities are presumed to rely on limited networks, and primarily for security rather than innovation (Bruce, 2003). However, the multiple forms of network resources, which micro-entrepreneurs draw from their various relationships, suggest that their innovation process has multiple steps and is more multi-dimensional than they are often given credit (McDade and Spring, 2005). Additionally, the analysis conveys a depth in imagining and strategizing that goes into the running of their small firm.

In turn, perceiving the micro-entrepreneurial experience with this added complexity would have implications upon how South Africa's policy circles, business development centres, and even local and international non-for-profit organizations that focus on community development interact with the local 
business community. Basic management skills are always valued in helping to promise the viability of small ventures. Nonetheless, the formally registered small enterprises of the current South African marketplace are presenting themselves to be complex organizations with complex processes. With this complexity come various demands by which to carry their innovative process forward with the restraints of their resource limitations by virtue of their size. In order to reconcile these constraints, the data reveals that the surrounding social structure of a small enterprise and its entrepreneur has entrepreneurial value. Implications for policy suggest that the surrounding networks that a small enterprise is embedded within needs to be fully understood and examined by those committed to entrepreneurial development. The policy framework for entrepreneurial development may be more relevant in taking into consideration the relationships that have significant roles in a small venture's viability, and institutionalizing means by which to make sure such links can be easily formed and that the engagement between the micro-entrepreneur and respective entity is productive and enjoyable. Ideas of policy innovations that may follow this direction are rewards and recognition given to formal entities, such as business support and development centres, noted by entrepreneurs to effectively assist in building their local ecosystem and the necessary links. In addition to the numerous networking events and conferences that take place for entrepreneurs to meet various types of people, policy may support and incentivize the creation of spaces with the deliberate intention of sparking creative thinking and experiential learning among entrepreneurs. Policy-makers may also want to consider how the identification and joining of emerging to established entrepreneurs, as well as necessary suppliers, distributers, and other parts of the entrepreneurial value chain can be made more easy and even encouraged. Creating and supporting entrepreneurial communities, where entrepreneurs can be linked to others for inspiration, exposure, and creativity, can also be incentivized by policy.

South Africa's diverse entrepreneurial society bears both proven and untapped potential in providing the local market with needed goods, service, and experiences that add value to people's lives while also being an outlet through which the talent embedded in the country is lucratively expressed. This paper hopes to have encouraged an alternative way of viewing the innovation process involved in an entrepreneurial class often underestimated for their complexity, and moreover, offers a framework by which to see their social structure as an active source of support and resources.

The intended audience for this research are policy makers, who are involved in building the South African ecosystem for entrepreneurial development. The findings aim to illuminate both the intangible and tangible resources that assist in an entrepreneur's progress with innovation that are sourced from their social capital. Secondly, emergent entrepreneurs and the business development organizations that support them are another targeted audience of this study. The study hopes to shift the discourse from that which focuses primarily on access to financial capital to a more holistic dialogue that highlights the multiple forms of capital that are of value to an entrepreneur's innovation, and furthermore, how those resources are embedded in one capital which all entrepreneurs - by virtue of their role as social beings - have access to. Thirdly, international organizations and local NGOs who are involved in shaping the local development context for innovation from emergent entrepreneurs are another set of stakeholder who will find this research relevant. Hey this study also targets these stakeholders. It is hoped that the findings will help to inform not only a South African specific understanding of the micro-entrepreneurial environment, but offer insight regarding the instrumental, socio-cultural, and cognitive needs of micro-entrepreneurs in similar environments.

\section{References}

Barr, A. 1995. 'The missing factor: Entrepreneurial networks, enterprises, and economic growth in Ghana', Centre for the Study of African Economies. University of Oxford.

Barr, A. 2002. 'Social capital and technical information flows in the Ghanaian manufacturing sector', Oxford Economic Papers, 52: 539559.

Bourdieu, P. 1986. The forms of capital. In Richardson, J. (Ed.). Handbook of theory and research for the sociology of education. New York, New York: Greenwood.

Bruce, M. 2003. 'Ethnic entrepreneurship: Preliminary findings from a South African study', Journal of Small Business and Entrepreneurship, 17(1): 47-62.

Fafchamps, M. \& Minten, B. 2002. 'Returns to social network capital among traders', Oxford Economic Papers, 54: 173-206.

Fleming, L., Mingo, S. \& Chen, D. 2007. 'Brokerage vs. cohesion and collaborative study creativity: An evolutionary revolution', Administrative Science Quarterly, 52: 443-475.

Fukuyama, F. 2002. 'Social capital and development: The coming agenda', SAIS Review, 22(1): 23-37.

Garcia, M. 2006. Social capital, networks, and economic development. Cheltenham, UK: Edward Elgar.

Granovetter, M. 1985. 'Economic action and social structure. The problem of embeddedness', American Journal of Sociology, 91(3): 481-510

Glaser, B. \& Strauss, A. 1967. The discovery of the grounded theory: Strategies for qualitative research. New Brunswick, New Jersey: Transaction Publishers.

Hite, J. \& Hesterly, W. 2001. 'The evolution of firm networks: From emergence to early-growth of the firm', Strategic Management Journal, 22: 275-286.

Hoang, H. \& Antoncic, B. 2003. 'Network-based research in entrepreneurship: A critical review', Journal of Business Venturing, 18: $165-187$.

Lipparini, A. \& Sobrero, M. 2004. 'The glue and the pieces. Entrepreneurship and innovation in small firm networks', Journal of Business Venturing, 9(2): 125-140. 
Mahembe, E. 2011. Literature Review on Small and Medium Enterprises' Access to Credit and Support in South Africa. Pretoria. Underhill Corporate Solutions. [online] http://www.ncr.org.za/pdfs/Literature\%20Review\%20on\%20SME $\% 20$ Access $\% 20$ to $\% 20$ Credit\%20in\%20South\%20Africa_Final\%2 0Report_NCR_Dec\%202011.pdf.

Mäkelä, M. \& Turcan, R. 2007. Building grounded theory in entrepreneurship research. In Neergaard, H. \& Ulhoi, J.P. (eds), Handbook of Qualitative Research Methods in Entrepreneurship. Edward Elgar Publishing, Incorporated.

McDade, B. \& Spring, A. 2005. 'The new generation of African entrepreneurs: Networking to change the climate for business and private-sector led development', Entrepreneurship \& Regional Development, 17(1): 17-42.

Oerlemans, L., Meeus, M. \& Boekena, F. 1998. 'Do networks matter? The usefulness of the economic network approach in analysing innovation', Royal Dutch Geographical Society, 89(3): 298-309.

Schilling, M. \& Phelps, C. 2007. 'Interfirm collaborations networks: The impact of large-scale network structure on firm innovation', Management Science, 53(7): 1113 - 1126.

Stauss, A. \& Corbin, J. 1990. Basics of qualitative research: Grounded theory procedures and techniques. London: Sage Publications.

Tallman, S. \& Phene, A. 2007. 'Leveraging knowledge across geographical boundaries', Organization Science, 18(2): 252-260.

Tsai, W. 2001. 'Knowledge transfer in intra-organisational networks: Effects of network position and absorption capacity on business unit innovation and performance', Academy of Management Journal, 44(5): 996-1004.

Pittaway, L., Robertson, M., Munir, K., Denyer, D. \& Neely, A. 2004. 'Networking an innovation: A systemic review of the evidence', International Journal of Management Review, 5/6(3\&4): 137-168.

Portes, A. 1998. 'Social capital: Its origins and applications in modern sociology', Annual Review of Sociology, 24:1-24.

Portes, A. \& Sensenbrenner, J. 1993. 'Embeddedness and immigration: Notes on the social determinants of economic action', The American Journal of Sociology, 98:1320-50.

Rogers, M. 2004. 'Networks, firm size and innovation', Small Business Economics, 22(2): 141-153.

Streeten, P. 2002. Reflections on social and anti-social capital. In Isham, J., Kelly, T., and Ramaswamy, S. (Eds.). Social Capital and Economic Development Well-being in Developing Countries. Cheltenham, UK: Edward Elgar.

Urban, B. 2011. 'Social capital configuration for necessity-driven versus opportunity-drieven entrepreneurs', South African Journal of Economic and Management Sciences, 14: 407-421.

Woolcock, M. 1998. 'Social capital and economic development: Toward a theoretical synthesis and policy framework', Theory and Society, 27(2): 151-208.
Woolcock, M. 2002. Social capital in theory and practice: Where do we stand? In Isham, J., Kelly, T., and Ramaswamy, S. (Eds.). Social Capital and Economic Development Well-being in Developing Countries. Cheltenham, UK: Edward Elgar.

Woolcock, M. \& Narayan, D. 2000. 'Social capital: Implications for development theory, research, and policy', The World Bank Research Observer, 15(2): 225-249.

Zukin, S. \& DiMaggio, P. 1990. Structures of capital: The social organization of the economy. Cambridge University Press. Cambridge, England.

Endeavor and Gordon Business School. 2009. The State of Entrepreneurship in South Africa. [Online] http://www.gibs.co.za/SiteResources/documents/The\%20Entrepren eurial\%20Dialogues $\% 20-\% 20$ State $\% 20$ of $\% 20$ Entrepreneurship $\% 20$ in\%20South\%20Africa.pdf

Thurton, N. \& Herrington, M. 2013. Global Entrepreneurship Monitor: South Africa Report 2012. [Online] http://www.gemconsortium.org/docs/download/2801

The World Bank. 2010. Assessing Africa's Pulse: This is the Time to Invest, Says World Bank Africa Chief Economist. [Online] http://web.worldbank.org/WBSITE/EXTERNAL/

COUNTRIES/AFRICAEXT/0,,contentMDK:22555665 menuPK: 2246551 pagePK:2865106 piPK:2865128 theSitePK:258644,00. html 